Cavanagh, S.L., Hurst, R.A.J. and Failler, A. (Eds.) (2013). "Introduction. Enfolded: Skin, Culture and Psychoanalysis.” In Cavanagh, S.L., Hurst, R.A.J. and Failler, A. Skin, Culture and Psychoanalysis (pp.1-15). Houndmills (UK): Palgrave Macmillan.

Author Accepted Manuscript (AAM)

\title{
Introduction
}

\section{Enfolded: Skin, Culture and Psychoanalysis}

Sheila L. Cavanagh, Angela Failler, and Rachel Alpha Johnston Hurst

The striking image on our book's cover is of a sculpture by artist Catherine Heard from an installation titled Efflorescence, first exhib-ited in 1997 at The Power Plant in Toronto. ${ }^{1} \mathrm{We}$ chose this artwork for its resonance with the themes, tensions and creativity striven for in the book. Efflorescence consists of several doll-like figures standing on pedestals under quiet, concentrated lighting. Displayed next to them are infants' garments, including christening gowns, laid out and inhabited by partial torsos and disembodied limbs in a ghostly gesture of absent presence. The sculptures are each stitched together using antique fabrics and forms made from wood, wool, wire, steel and human hair. The most captivating feature of the work, however, is the tendrils, daisies, black thorn and poppy blossoms embroidered onto the "skins" of the dolls and across the folds of the garments. While perhaps unremarkable in and of themselves as subjects of traditional embroidery, the floral motifs swathe Heard's effigies in patterns that, from a distance, resemble crops of reddened pustules, scabs, or bleeding sores: skin disease in bloom. Only when viewed up close do these shapes come into focus as delicate flowers (Heard, 2001, p. 44). Heard has literally and figuratively interwoven two different connotations of "efflorescence" from the milieus of botany and dermatology: efforescence (1) The process, or period, of flowering; (2) A morbid redness, or rash of the skin (from The Shorter Oxford Dictionary cited in Fabo, 2001). The effect is to render the sculptural displays at once intricately beautiful and piteously abject. In the artist's own estimation, viewers of the work are both attracted to and repelled by it. ${ }^{2}$

The fact that skin, or representations of skin, can signify beauty and abjection at once, or evoke attraction and repulsion simultaneously draws attention to skin is capacity to bear multiple and contradictory meanings; skin doth fester and flower. ${ }^{3}$ It also highlights the propensity for skin to serve as a trigger of potent affective, even visceral response. Moreover, belying its status as mere surface matter skin becomes a site for the projection and exposure of deep-seated cultural, political and psychical investments. Frantz Fanon made tangible these propensities in his renowned work Black Skin, White Masks (1952) where he describes racism as the "epidermalization of inferiority" (2008 [1952], p. xv). "Epidermalization" is a two-fold process according to Fanon. The first fold involves the projection of inferiority onto the bodies of people of color in colonial contexts through economic and cultural marginalization, reducing them to nothing more than skins, or husks, void of interiority, mindfulness or soul (Oliver, 2001, p. 24). The second fold involves the introjection or absorption of racist cultural values into the psychic lives and embodied experience of the oppressed, resulting in their so-called inferiority complex 
(Fanon, 2008 [1952], p. 2). What Fanon attempts to account for in theorizing this enfolded "epidermal racial schema" (p. 92) is both the physical and psychical impact of skin as a marker not only of social difference but also of human value and recognition. His work, that is, imagines skin as materialized through relations of power in ways that interimplicate culture, psychical life and embodied experience.

In this spirit of interimplication, the main title of our introductory chapter-"Enfolded"captures the broad aim of this book: to explore how skin is made meaningful through the enfolding of culture, psychical life and embodiment. Skin is a complex affair. It cannot be taken for granted as merely organic matter, nor as a passive surface onto which social meaning is straightforwardly inscribed. As a condition of human subjectivity and a primary site of its negotiation, skin bears multiple, complex pressures from both within and without, and generates a range of expressions particular to persons $\}$ cultures and environments. Skin also separates us from and connects us to others and to objects in the world. We feel our skins as intimately our own, and yet they are continually shared by encounter and exchange. In the process, skin is imbued with conscious and unconscious meanings, including those we attach to it through constructions of sex, gender, sexuality, age, race, religion, nationality, class, (dis)ability and so forth. Skin, in short, has a biological life, a social life, a fantasy life, a somatic life, a political life, an esthetic life, a life in the "lived body" and a cultural life - all of which inform one another to shape what it means and how it feels to inhabit skin. Appreciating the richness and multidimensionality of skin is no minor task. At the very least, an interdisciplinary approach is required. This book is one such undertaking.

Skin, Culture and Psychoanalysis sets out to query the intersection of cultural and psychical meanings of skin in the contemporary moment as skin responds to new (and old) demands and articulations. The chapters herein address a variety of topics including the symbolic dominance of white skin, racialization, tattooing, cosmetic surgery, fabric "skins," skin eruptions, second skins, the skin in self-harm and skin as a site of psychic repair. Our contributors engage an array of objects and approaches from the clinical domain, literary fiction, television, film, video art, photography, fashion design and poetry. In doing so, they highlight the situation of skin as a socially and culturally mediated exterior simultaneously negotiated at the interior or psychical level. Our collection places skin at the center of inquiry, rather than using it as a jumping-off point from which to explore "deeper" or "thicker" issues, which tends to happen when skin is treated synecdochically as a stand-in for the body. Here, skin is a cultural object, and a psychical object, in its own right.

This project bridges and builds upon existing psychoanalytic and cultural studies literature on skin. The crucial contribution of psychoanalysis has been to notice how skin is neither simply organic matter nor an effect of cultural-discursive practices alone, but implicated in and mediated by unconscious phantasy. ${ }^{4}$ The work of French psycho-analyst Didier Anzieu $(1989 ; 1990)$ is central to this literature for his conceptualization of the "skin ego," which extends Freud's notion of the ego as "a mental projection of the surface of the body" (Freud, 1923, p. 26) as well as other references in Freud's writings on erotogenic zones, the touching drive and psychical dimensions of skin disease (Ulnik, 2008, p. 5). In brief, Anzieu uses the notion of "skin ego" to posit that sensations connected to the material skin are the basis upon which the psychic apparatus (the bodily ego, sense of self) is formed. He arrives at this theory having worked with 
patients living with various dermatological conditions. Psychoanalytic case studies, like Anzieu's, have thus provided important understandings of how psychical distress can manifest through the skin of the individual and, alternatively, how skin irritation or dis-ease can cause psychical distress - topics variously addressed in the present collection by Sheila Kunkle, Angela Failler and Erica D. Galioto who explore "surfacings" of skin eruptions and self-cutting.

The work of French psychoanalyst Jacques Lacan also frames several of our studies on skin. While Anzieu was critical of Lacan's language-centered paradigms and the difficulties they pose for theorizing the somatic and sensorial components of skin, we remain persuaded by Patricia Elliot's (2001) insistence that embodiment cannot be fully theorized by relying solely upon body-centered theories since sexed embodiment, in particular, is also produced by psychic processes structured by language and discourse. Without dismissing the important phenomenological components of the skin and the somatic elements of sexed embodiment, Elliot contends that we need a sophisticated theory of language, such as that offered by Lacan, to understand how the skin ego is animated in culture and psychically invested. In keeping with Elliot's invitation to consider phenomenology and psychoanalysis together, Skin, Culture and Psychoanalysis then offers a rich assortment of chapters that use Lacanian and Lacanian-inspired theory in innovative ways to theorize the skin. Thus while Anzieu presented his formative work on the skin ego as a paradigmatic departure from Lacanian scholarship, we believe it is fruitful to use the two theorists in concert (and to sidestep a binary between the two).

Individual experiences of skin must be also recognized as located within particular cultural and social contexts. The argument of our collection, that to take the skin seriously we must enfold discussions of skin from psychoanalytic and cultural studies literature together, aims to account for this scenario - the individual in context — as did Fanon. Cultural studies approaches to skin rooted in social, historical and cultural contexts offer important sustained and critical analyses of the politics of skin, especially those tied to processes of racializa-tion and other constructions of social difference. Sara Ahmed and Jackie Stacey's edited collection Thinking through the Skin (2001), for instance, is a significant precursor to ours in that it endeavors to build on the engagement of feminist theory with the body through the skin as a site of cultural inscription as well as agentic potential. The essays in their collection draw upon phenomenological, postcolonial, psychoanalytic and feminist theories in attempts to think through the skin (Ahmed and Stacey, 2001, p. 1) as a means of critical engagement with embodied experiences including pregnancy, conjoined twinship, clitoridectomy, body art, self-harm and "virtual" touch. While we are similarly invested in an interdisciplinary approach, our book uses psychoanalytic theory more consistently as a central, organizing mode of inquiry. Each of the authors in our collection offers a psychoanalytic approach to skin, adding dimension to the stakes raised in Ahmed and Stacey's important text.

Our collection is also in implicit conversation with a number of sole-authored works that demonstrate the possibilities we identify for an enfolded analysis of skin, bridging psychoanalytic and cultural studies. In Second Skins: The Body Narratives of Transsexuality (1998), for instance, Jay Prosser makes use of Anzieu's concept of the skin ego to theorize the desire to change sex or, rather, to bring the physical body into alignment with a psychicallyinvested body image. Prosser underscores the significance of culture in shaping the somatic and psychical shifts involved in transsexual transitions. By doing so, he demonstrates the potential 
for pairing Anzieu's body-centered psychoanalysis with cultural theory towards a valuable account of skin in situ, as do Andrew Hock Soon Ng and Shawn Thomson in the present collection, deploying Anzieu's scholarship to consider the skin's relationship to cultural practices such as tattooing and art spectatorship respectively.

Another example of an enfolded analysis of skin can be found in Allessandra Lemma's Under the Skin: A Psychoanalytic Study of Body Modification (2010). Here, Lemma employs an understanding of skin as an interface between the psychical world and the cultural world through a study of body modification. Drawing from her experience as a psychoanalyst, she discusses case studies and interviews with people who body modify with films, fiction and art. She argues for body modification as a fundamentally cultural process that marks the body in relation to cultural and societal norms, while at the same time highlighting how this marking has profound psychical effects and meanings. In Consensuality: Didier Anzieu, Gender and the Sense of Touch (2009), Naomi Segal carries out an enfolded analysis through the concept of the book's title. "Consensuality," a term used by Anzieu to convey the intersensorial or convergent function of the skin ego, is here reanimated not just through Segal's rereading of Anzieu's work but by contextualizing Anzieu's theories within his (and his mother's) life histories. This layered and rather intimate treatment of Anzieu comes to underpin Segal's subsequent interpretation of a series of cultural objects including accounts of and by certain public figures, literary works, sculpture and films. Her book, in other words, makes consensual psychoanalytic theorizing with intellectual and esthetic expressions of how lives, love and loss are "mediated through our organ of touch" (Segal, 2009, p. 4). In doing so, she enlivens skin as a point of personal and cultural convergence.

In yet another uniquely transdisciplinary study, Anne Anlin Cheng's Second Skin: Josephine Baker \& the Modem Surface (2011) situates 1920s burlesque star Josephine Baker and the encoding of her black female skin within a history of the development of modern esthetics and the popularization of skin tropes across fashion, film, art, architecture and psychoanalysis. Cheng understands Baker's performance and iconography to be expressions of a particular modernist vision of the body underpinned by a cultural fantasy of "second skin." From this perspective, Baker is not simply/solely an object penetrated by colonial-masculinist desire or the racial fetishist's gaze, but an innovator in her own right, performing her nakedness "like a sheath" (Cheng, 2011, p. 1), smooth and shimmering as the idealized modern surfaces ushered in by the age of mechanical reproduction and new technologies of manufacture and display. In our collection, Sara Davis's discussion of Nella Larson's novel Quicksand (1928) (of the same era as Bakeris fame), attempts to carve out a way of seeing the novel's protagonist, Helga Crane, that speaks not just to her objectification but to ways in which she fetishistically clothes her "yellow satin skin" to exercise agency amidst the racist attention she is subjected to. Similar to Cheng, then, Davis understands "raced skin" relationally and complexly as a means of challenging a modern "racial epidermal schema" that would simply align black bodies with "dumb flesh" (Cheng, 2011, p. 14).

Claudia Benthien's Skin: On the Cultural Border Between Self and the World (2002 [1999]) is a psychoanalytically informed cultural history of skin where skin is usefully conceptualized as a "symbolic surface between the self and the world" (p. 1). Through representations of skin across the biological and medical sciences, arti literature and new media, Benthien traces how views of 
skin have shifted in recent centuries towards a preoccupation with penetrating or crossing the skin-boundary, despite an ongoing investment in the notion of skin as a rigid integument. Benthien's methodology finds its complement in our collection in Rachel Alpha Johnston Hurst's chapter, which enfolds a genealogy of skin over decades in the cosmetic surgery industry with representations of skin in fashion design, poetry and television. Hurst finds inherent contradictions in the way that skin is conceptualized as textile-like (endlessly transformable, customizable) in these contexts, similar to Benthien's identification of the paradoxical penetrable/impenetrable fantasy characteristic of contemporary imaginings of skin.

Finally, taken altogether, our collection builds on Steven Connor's assertion in The Book of Skin (2004) that the skin is a milieu, that is, "a place of minglings, a mingling of places" (p. 26).

Connor is interested in the hyper-visibility of skin in Western cultures, folding his analysis of the visual back upon the aspects of skin that evade vision and employ the other senses like touching, smelling and tasting. Rather than thinking through the skin as a container, boundary or cultural surface, Connor uses the conceptualization of the "milieu" in Michel Serres's philosophy to create a more versatile metaphor, which can accommodate the skin1s situation in history, culture and society. His metaphor of the milieu is intended to encompass the individual (the singular experiences of the senses) as well as the cultural (the meaning made of sensational experiences, the way difference is established and reproduced). We extend Connor's metaphor of the milieu in this collection through the implementation of a psychoanalytic approach to the study of the individual within culture, and culture within the individual. In other words, we interpret psychic life and the individual experience of skin as always already implicated in cultural life, and vice versa.

The approaches taken by the authors of the chapters in our collection vary significantly in their theoretical perspectives. As a result, readers will note productive differences and points of convergence between them. For example, while Sheila Cavanagh and Sheila Kunkle both use Lacanian frameworks to consider popular film, they conceptualize "ruined" or "abject" skin in very distinct ways. Stella North and Shawn Thompson have differing interpretations of the relationship between Freud and Anzieu, yet each take the skin ego to be paramount to their respective investigations of the clothing ego and spectatorial desires. Angela Failler and Erica Galioto both theorize self-harm or skin cutting as a means of psychic self-preservation; Failler draws on object relations theory while Galioto incorporates Lacan. Nevertheless, what the chapters all have in common is their commitment to privileging neither conscious nor unconscious dynamics of skin. They take an approach, in other words, that is enfolded, envisioning the skin as milieu through which to think about complex relationships between the social/cultural and the psychical towards expanding skin's political, material and psychical significance, recognizing its capacities for vulnerability and resilience in new light.

Our collection begins with two theoretically descriptive chapters: one informed by the now seminal writing by Didier Anzieu on the skin ego and the psychic envelope (Lafrance), and the second utilizing a Lacanian approach to comedic skins (Kunkle). These two chapters map out some of the most analytically useful concepts and approaches to skin studies. Focusing on Anzieu's texts, The Skin Ego (1989 [1985]), A Skin for Thought (1990 [1986]) and Psychic Envelopes (1990), Lafrance offers a critical analysis of Anzieu's conception of the body's surface - its skin - as a crucial constituent of the mind's structures and functions. Anzieu uses 
the skin to consider psychic and somatic functions central to sensory experience, subjectivity and embodiment. Lafrance explicates how Anzieu's formulations of the skin ego and the psychic envelope are, in fact, non-dualistic and non-deterministic, thus making room for cultural inquiry. By arguing that Anzieu's work on the skin provides cultural theorists with analytic tools to theorize embodied subjectivity, Lafrance makes a powerful case for the use of psychoanalytic theories of skin in cultural studies.

The second chapter, by Sheila Kunkle, titled "Comedic Skin Eruptions: A Psychoanalytic Reading of Austin Powers" uses Lacanian psychoanalysis to grapple with the meaning of skin anomalies, excrement and abject bodily fluids in Mike Myers's films. Kunkle contends that cinematic skin eruptions are comedic because they are physical materializations of the objet $a$, or the object cause of desire, best understood through recourses to networks of signifiers, alienation and otherness. Kunkle explains that we relate to our skin as a membrane that can inexplicably take on a life of its own, as something we need to continually monitor. Myers's films reveal that skin eruptions, which signal something out of order, threatening and chaotic, also retain something of the comedic; and comedy offers us a mechanism to play with the content of our fears. Ultimately, Kunkle demonstrates how comedy allows us to reconfigure that which we dread about corporeal eruptions and anomalies appearing directly on the skin.

In Chapter 3, "The Surfacing of the Self: The Clothing-Ego," Stella North introduces the concept of the "clothing-ego" to capture the use of clothing as an experiential, supplementary skin. North contends that clothing is central to Anzieu's figuration of the skin ego. She specifies that clothing, textiles and fashion are crucial to the foundation and function of the skin ego and that they are relevant to theorizing embodiment. Attention to clothing enables North to theorize the interface between culture and skin ego functioning, the psychic and the somatic, the internal and the external. North makes a persuasive argument for considering how cloth, like the skin, becomes an interstitial surface that is, in fact, constitutive of the subject in culture.

The fourth chapter, by Sara Davis, titled "The Red Thing: Fabrics and Fetishism in Nella Larsen's Quicksand," similarly analyzes the relationship between skin and clothing but through attention to gender, race, class and geographical context. Davis's literary analysis of Larsen's 1928 novel utilizes Freud's theories of fetishism to understand the metaphoric function of clothing in the novel to mediate sexual and racial difference. Fashion becomes a screen, covering and revealing the skin, but in culturally specific ways. The protagonist, Helga Crane, is a young woman of mixed-race heritage who travels from the southern United States to bustling Harlem to Denmark and back. Her "yellow satin" complexion is subject to fetishistic attention and read differently in each context. Helga adorns herself in colorful fashions to conceal her racial difference but ultimately finds her "skin-substitute" to be an insufficient guard against her racial subjection. By theorizing the multiple uses of clothing to resist, contradict and confirm Helga's racial difference, Davis chronicles the various ways the protagonist uses fashion to negotiate a gendered and racialized subject position in post-colonial contexts. The intimate relationship between skin and clothing in post-colonial cultures is an occasion not only for fetishistic and racially specific objectification but for its contestation.

Andrew Hock Soon Ng's Chapter 5 offers a psychoanalytic read-ing of "The Tattooer" written by Junichirō Tanizaki during the Meiji Period (1852-1912) and, more specifically, how a spider 
tattoo on the maiko (amateur geisha) character's back ignites the skin ego in the short story. As a gendered and culturally specific insignia of desire, the tattoo functions here to infuse the body of the tattooed woman with the diabolic (and sadistic) desire that was formerly a property of the tattoo artist, Seikichi. Prior to the tattoo, the maiko was submissive and demure. By using Anzieu's conception of the skin ego, $\mathrm{Ng}$ offers a powerful interpretation of how Seikichi's desire is transferred onto the maiko by inscribing a black widow onto her back with piercing needles. She becomes not only a conduit for his sadistic desire but a canvas upon which his vision of the ideal (and necessarily enigmatic) woman is encrypted. $\mathrm{Ng}$ offers invaluable insight into the gendering, symbolism and hidden homoeroticism of Tanizaki's fiction, and a compelling argument for how the act of marking the body can enable transferential power relations whereby gendered relations of desire are reconfigured.

In Chapter 6, "The Skin-Textile in Cosmetic Surgery," Rachel Alpha Johnston Hurst explores how skin is conceptualized as a textile in cosmetic surgery through three examples that highlight the gendered, racialized and sexualized dimensions of this phenomenon. She argues that there is a Western cultural preoccupation with thinking about skin as analogous to fabric, which increasingly repudiates the violence implicit in this conceptualization of the skin in cosmetic surgery. This understanding contributes to the fantasy of the mutable body and the normalization of cosmetic surgery through association with fashion. Elsa Schiaparelli's Tear-Illusion Dress (1937) is an evening gown and headscarf sewn from a fabric printed with a Dali design that estheticizes the flaying of skin, and occurs within a time of experimentation in cosmetic surgery and as a critique of bourgeois denial of impending war in Europe. "Face Lift" (1961) is a poem by Sylvia Plath that offers a metonymic chain of fabrics that incompletely shroud the cuts into the facial skin-textile, and historically reflects a time of optimism for face-lifting surgeries in the 1950s and 1960s and idealization of American middle-class privacy. Rick Floyd's promotional trailer for season six of the television series Nip/Tuck (2009) is a contemporary representation of the textility of skin in cosmetic surgery par excellence. Sexualized garment sweatshop workers garbed in cheon-gsams cut and sew the skin-textile for Nip/Tuck's cosmetic surgeon protagonists, a representation that promises an endless, bloodless and painless proliferation of cosmetic surgical procedures within a hybrid global market of surgical fashion.

In Chapter 7, "Narrative Skin Repair: Bearing Witness to Mediatized Representations of SelfHarm," Angela Failler explores what conditions might be necessary for thinking critically about the dilemma of self-harm when visually mediated representations serve as the pri-mary means of engagement. In particular, the author asks how and why mediatized representations of self-harm are especially complex sites of spectatorship, and suggests what the implications of this are for the potential to cultivate empathic understandings of self-harm and those who practice it in the "real world." Failler's methodology involves extrapolating from understandings of self-harm and ways of listening in the psychoanalytic context to the "second-hand" context of media witnessing. Theoretically, the chapter draws on Esther Bick's (1968) object relations skin containment theory, Jill Bennett's (2005) notion of "empathic vision" in relation to trauma art, and case studies by contemporary psychoanalytic therapists. The chapter also centers on Hope Peterson's video artwork Surface Damage as a primary example towards exploring these issues. Failler begins with the premise that self-harm can be productively understood as a means of survival in the wake of psychical trauma, and argues convincingly that practices of self-harm are invitations (albeit ambivalent ones) to witness the markings of internal trauma. In turn, it is 
proposed that thoughtful bearing witness can open up an intersubjective space for narrative skin repair.

Erica D. Galioto's chapter, titled "Split Skin: Adolescent Cutters and the Other," argues that cutting enables the subject to forge a psychic split essential to ego-functioning and is, thus, palliative as opposed to self-destructive. Using Lacanian psychoanalysis rather than object relations theory, Galioto nonetheless draws conclusions comparable to those of Failler with respect to how cutting enables the subject to negotiate a self in the wake of trauma. Galioto's unique contribution is to show how cutting is a means to complete a psychic split incomplete in the Lacanian mirror stage. Cutting enables self-recognition through rupture; a scarred border appears demarcating an inside and outside that was, prior to the rupture, indecipherable to the subject. Galioto situates the cutter in relation to the Lacanian Other and the Other's desire in order to underscore the intersubjective dimensions of cutting. Drawing on Patricia McCormick's novel Cut (2000) as a case study, Galioto demonstrates how skin tells a story, insisting upon the radical heterogeneity of each cutter's personal history while contending that each cutter attempts to forge a psychic split essential to life. This chapter gives careful attention to unconscious dynamics routinely ignored in "self-help" literature and sheds light on the paradoxical relationship between pain and relief.

In Chapter 9, Shawn Thomson takes the question of cutting into the domain of photographic art. This chapter, titled "Disrupting the Skin-Ego: See-Sickness and the Real in The Flagellation of a Virgin," uses Lacanian psychoanalysis to theorize skin-ego functioning in audience reception of Aubie Golombek's photos of butchered flesh. Spectators' difficulty viewing the 21 images of raw, butchered flesh (animal parts and rotting fruit without skin) is accounted for with recourse to the Lacanian Real. Thomson also uses Anzieu's concept of the skin-ego to consider how the imagery disrupts the viewer's sense of his/her skin-ego as a protected and closed whole. This disruption proceeds by rupturing both what is presented in the skin of the flesh and how it is seen through the skin of the photographic plane. This dual rupture, more than frustrating any mode of identification, opens the necessary space for identification and change. In this, the prints also enable an important extension of Kaja Silverman's theory, of identification by localizing the disruption of idealized identities at the very surface of the skin.

In the final chapter, Sheila L. Cavanagh builds upon Kaja Silverman's analytic of the bodily ego to theorize audience reception as indicated in film reviews of Patty Jenkins's 2004 film Monster starring Charlize Theron. In "WWhite Trash': Abject Skin in Film Reviews of Monster,"

Cavanagh uses psychoanalytic concepts like fetishism, abjection, identification and disavowal to theorize the use of white, feminine skin in Hollywood film to conceal troubling knowledge. More specifically, she argues that troubling knowledge about the tragic life story of Aileen Wuornos, America's most notorious serial killer (depicted in the film), is refused through preoccupations with Hollywood skin and body transformations. By analyzing the attention paid to actor and model Charlize Theron and her transformation (from beautiful blonde Hollywood "sex symbol" to ugly, blasphemous whore-Aileen Wuornos - and back again), she considers how white, feminine skin is either fetishized or seen as abject. Cavanagh contends that we may understand refusals to identify with Wuornos, and her traumatic life story, by using Kristeva's analytic of abjection in relation to the Freudian conception of the fetish. She concludes by 
offering preliminary notes about how we might think queerly about the abject and the fetish in film and popular culture.

Skin, Culture and Psychoanalysis offers a unique contribution to the literature by way of utilizing cultural studies and psychoanalytic modes of inquiry concurrently to theorize skin. When deliberating on how best to present and organize our collection we were reluctant to group chapters into sections according to cultural objects, theoretical approaches or thematic connections. Sectional organization can be both too permeable and too rigid. We wanted instead to facilitate unanticipated trains of associations - the mapping and lines of skins and chaptersthat might be foreclosed by clearly delineated book sections. We invite the reader to make their own associative connections across, between and within chapters, giving life and form to that which is new and unexpected.

\section{Notes}

1. This artwork is now part of the collection of the Art Gallery of Hamilton.

2. This observation was shared by Catherine Heard (artist) in conversation with Angela Failler (co-editor), March 5, 2012.

3. This phrasing was inspired by Haggo's review of Heard's Effloresence titled "Beauty and Horror Fester and Flower" (see Bibliography for full reference).

4. The term "phantasy" exists in some psychoanalytic writing to distinguish a mental representation that is unconsciously formed through the internal and external world and then projected onto other objects from fantasy, a product of the conscious imagination that represents a wish-fulfillment. However, this distinction is not used consistently throughout psychoanalytic theory, and often fantasy is used without distinction.

\section{Bibliography}

Ahmed, S., and J. Stacey (eds) 2001. Thinking through the Skin. London: Routledge.

Anzieu, D., 1989 [1985]. The Skin Ego, trans. C. Turner. New Haven: Yale University Press.

Anzieu, D. (ed.) 1990. Psychic Envelopes, trans. D. Briggs. London: Kamac.

Anzieu, D., and G. Tarrab (eds) 1990 [1986]. A Skin for Thought: Interviews with Gilbert Tarrah on Psychology and Psychoanalysis, trans. G. Tarrab. London: Kamac Books.

Bennett, J., 2005. Empathic Vision: Affect, Trauma, and Contemporary Art. Stanford California: Stanford University Press.

Benthien, C., 2002 [1999]. Skin: On the Cultural Border between Self and the World. New York: Columbia University Press.

Bick, E., 1968. "The Experience of Skin in Early Object-Relations," International Journal of Psycho-Analysis, vol. 49, pp. 484-6.

Cheng, A. A., 2011. Second Skin: Josephine Butler and the Modern Surface. New York: Oxford University Press.

Connor, S., 2004. The Book of Skin. Ithaca: Cornell University Press. 
Elliot, P., 2001. “A Psychoanalytic Reading of Transsexual Embodiment.” Studies in Gender and Sexuality, 2(4), pp. 295-325.

Fabo, A., 2001. Catalogue essay for the exhibition Efflorescence by Catherine Heard (artist). Medicine Hat: Medicine Hat Museum and Art Gallery.

Fanon, F., 2008 [1952]. Black Skin, White Masks, trans. R. Philco:X. New York: Grove Press.

Floyd, R., 2009. Promotional trailer for season six of Nip/Tuck. Available from: http://www.youtube.com/watch?v=0TfBsrivzFQ [Accessed June 23, 2010].

Freud, S., 1923. "The Ego and the Id," in Collected Papers. Standard Edition, vol. 19, pp. 12-66.

Golombek, A., 2004. The Flagellation of the Virgin [photographic series].

Haggo, R., 2011. "Beauty and Horror Fester and Flower," The Spec. Available from: http://www.thespec.com/print/article/318876 [Accessed April 9, 2012].

Heard, C., 2001. "Artist's Statement for Efflorescence," Artichoke, special edition, No. 1, p. 44.

Kristeva, J., 1982 [1980]. Powers of Horror: An Essay on Abjection, trans. Leon Roudiez. New York: Columbia University Press.

Larsen, N., 1928. Quicksand, Penguin Twentieth-Century Classics edition. New York: Penguin Classics.

Lemma, A., 2010. Under the Skin: A Psychoanalytic Study of Body Modification. London and New York: Routledge.

McCormick, P., 2000. Cut. New York: PUSH.

Monster, 2003. Film. Directed by P. Jenkins. USA: Media 8 Entertainment.

Oliver, K., 2001. Witnessing: Beyond Recognition. Minneapolis: University of Minnesota Press.

Plath, S., 1971. Crossing the Water: Transitional Poems. New York: Harper and Row.

Prosser, J., 1998. Second Skins: The Body Narratives of Transsexuality. New York: Columbia University Press.

Salecl, R., 2001. "Cut in the Body: From Clitoridectomy to Body Art," in Thinking through the Skin, eds. S. Ahmed and J. Stacey. New Yok: Routledge, pp. 21-35.

Segal, N., 2009. Consensuality: Didier Anzieu, Gender and the Sense of Touch. Amsterdam and New York: Rodopi.

Silverman, K., 1996. The Threshold of the Visible World. New York/London: Routledge.

Surface Damage, 1992. Film (DVD, 3/41 SP). Directed by H. S. Peterson. Canada: Video Pool.

Tanizaki, J., 1967 [1910]. "The Tattooer (Shisei, 1910)," in Seven Japanese Tales, trans. H. Hibbert. Tokyo: Tuttle, pp. 160-9.

Ulnik, J., 2008. Skin in Psychoanalysis. London: Karnac.

Wegenstein, B., 2008. Getting Under the Skin: The Body and Media Theory. Cambridge: MIT Press.

Žižek, S., 1994. The Metastases Of Enjoyment: Six Essays On Woman And Causality. London/New York: Verso.

Žižek, S., 1997. The Plague of Fantasies. London/New York: Verso.

Zizek, S., 2001. Enjoy Your Symptom! Jacques Lacan in Hollywood and Out. London/New York: Routledge. 